\title{
Comparative Effects of Thermal Treatments on the Shape Memory Phenomenon of Fe-Mn-Si and Fe-Mn-Cr-Ni-Si Steels
}

\author{
T. Bouraoui, A. Van Neste* and B. Dubois \\ Material Physics, L.I.S.S. MA., I.S.C.M., 3 rue F. Hainaut, 93407 Saint Ouen, France \\ * Dept. Mines et Métallurgie, Université Laval, Quebec G1K7P4, Canada
}

\begin{abstract}
Two shape-memory steels were water quenched after one hour at $873 \mathrm{~K}$ to keep a stable austenitic structure at $298 \mathrm{~K}$. The best values of the shape memory recovery were obtained after a $2.5 \%$ strain followed by an annealing at $873 \mathrm{~K}$. In fact, immediately after water quenching from $1323 \mathrm{~K}$, the Fe-Mn-Si alloy did not present the forward $\gamma \rightarrow \varepsilon$ transformation. The transformation was detected after maintaining $48 \mathrm{~h}$. at $298 \mathrm{~K}$ and was considered as complete after $480 \mathrm{~h}$, , using electrical resistivity measurements. Samples of the two steels were slowly cooled from $1123 \mathrm{~K}$ under vacuum : the Fe-Mn-Si alloy showed completely ordered $\mathrm{D} 03+\mathrm{B} 2$ structures and was ferromagnetic whereas the Fe-Mn-Cr-Ni-Si steel was a mixture of the $\gamma$ phase and the $\mathrm{D}_{03}+\mathrm{B}_{2}$ structures.
\end{abstract}

\section{INTRODUCTION}

From previous studies on the Fe-Mn-Si shape memory steel (named F.M.30) the chemical composition was found suitable to consider this alloy as a good model to approach the behaviour of that class of shape memory steels $(1,2)$. To improve corrosion resistance, it was demonstrated that chromium and nickel were essential additions. The influence of some thermal treatments are now studied on the structure and the properties of the two alloys.

\section{EXPERIMENTAL.}

The F.M. 30 steel from AUBERT and DUVAL Co. was compared with an experimental alloy (named A.V.E.) melted, cast and shaped at the LAVAL University.

The chemical compositions ( in wt\%) were the following:

- Mn: 31.6 - Si: 6.45 - C: 0.018 - N: 0.0052- S: 0.0079 for the F.M.30 steel.

- Mn: 18.5 - Si: 4.75 - Ni: 5.03 - Cr: 7.96 - Mo: 0.15 - C: 0.016 for the A.V.E. alloy.

Samples $\left(0.5 \times 10 \times 60 \mathrm{~mm}^{3}\right)$ were cut from the bars and then mechanically and electrolytically polished. Structural studies were carried out by light optical microscopy and X-ray diffraction (KaCo target). Transformation temperatures were determined by electrical resistivity and dilatometric measurements. Dilatometry was also used to obtain the amplitude of the shape memory recovery after $2.5 \%$ and $4.5 \%$ strains, given respectively to the samples on a tensile machine. 


\section{RESULTS}

\subsection{As received samples.}

After removal of the oxide layer, room temperature X-ray diffraction patterns showed a $(\gamma+\varepsilon)$ phase mixture for the F.M.30 steel whereas the A.V.E. was fully an austenitic phase. The grain size of this latter alloy was 20 to $50 \mu$ m i.e. 4 to 10 times smaller than of the F.M.30 alloy.

From electrical resistivity measurements, the transformation temperatures were :

-for the F.M.30 alloy, during the first cycle of heating (R.T $\rightarrow 573 \mathrm{~K} \rightarrow \mathrm{R} . \mathrm{T}$.) at $2 \mathrm{~K} . \mathrm{mn}^{-1}$ :

$$
\text { As }=387 \mathrm{~K}, \text { Af }=413 \mathrm{~K} \text {. }
$$

-for the two alloys, during the first cycle of cooling (R.T. $\rightarrow 123 \mathrm{~K} \rightarrow$ R.T.), it was possible to determine - with help of previous magnetic studies $(3,4)$-the antiferromagnetic transition temperatures $\mathrm{T}_{\mathrm{N}}^{\gamma}$ and $\mathrm{T}_{\mathrm{N}} \varepsilon$ (Fig, 1 and 2). Moreover, results presented in Fig. 1 show that the forward transformation $\gamma \rightarrow \varepsilon$ for the F.M.30 steel is not completely arrested at $\mathrm{T}_{N} \gamma$ but at a temperature called $\mathrm{Mf}^{\prime}<\mathrm{T}_{\mathrm{N}}^{\gamma}$, as obtained by the overlapping of the resistance variations during the cooling and the heating. Results are given on Table I.

\begin{tabular}{|c|c|c|c|c|}
\cline { 2 - 5 } \multicolumn{1}{c|}{} & Ms (K) & Mf $(K)^{\prime}$ & $\mathrm{T}_{N^{\varepsilon}}(\mathrm{K})$ & $\mathrm{T}_{\mathbf{N}}^{\gamma}(\mathrm{K})$ \\
\hline F.M.30 & 273 & 243 & 173 & 265 \\
\hline A.V.E. & 253 & 233 & 143 & 203 \\
\hline
\end{tabular}

Table 1

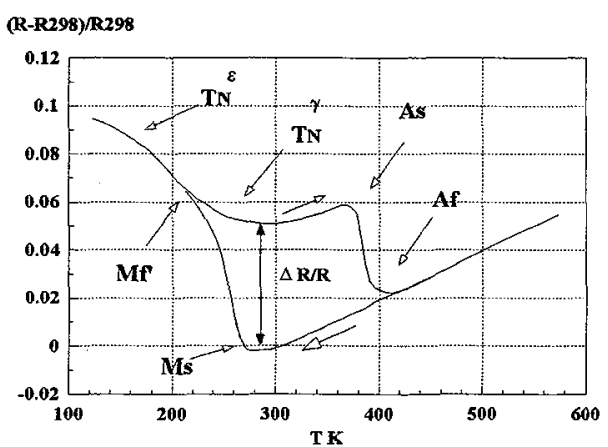

Fig. 1: Electrical resistance measurements of the as received F.M.30 steel

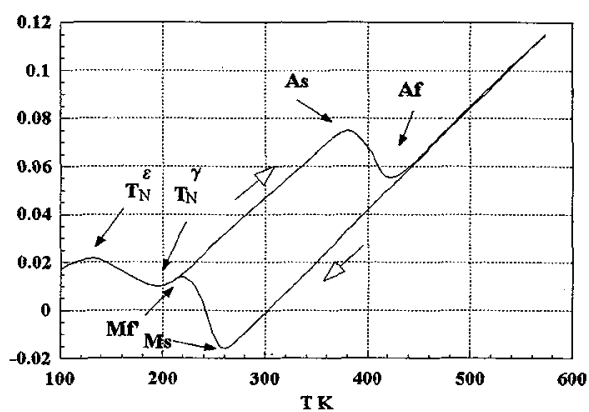

Fig. 2: Electrical resistance measurements of the as received A.V.E. alloy 


\subsection{Samples quenched from $1323 \mathrm{~K}$.}

After $15 \mathrm{mn}$ at $1323 \mathrm{~K}$, a water quenched sample of the A.V.E. steel presented an austenitic structure, which did not change with the maintaining time at $298 \mathrm{~K}$. The situation was different with the F.M.30 alloy. Immediately after water quenching from $1323 \mathrm{~K}$, electrical resistance measurements presented no variation during the R.T. $\rightarrow 523 \mathrm{~K} \rightarrow \mathrm{R} . \mathrm{T}$. temperature cycle.(Fig.3a). After maintaining $48 \mathrm{~h}$. at $298 \mathrm{~K}$, the As-Af temperature range was detected and a resistance ratio $\Delta R / R=0.6 \%$ was measured (Fig. $3 b$ ). This ratio reached a maximum value $(\Delta \mathrm{R} / \mathrm{R}=2.6 \%$ ) after maintaining the sample $280 \mathrm{~h}$. at $298 \mathrm{~K}$ (Fig. 3c) and remained practically constant after more than $280 \mathrm{~h}$. The As and Af temperatures did not change noticeably. Similar phenomena were observed on the same alloy when the quenching temperature was higher than $873 \mathrm{~K}$.

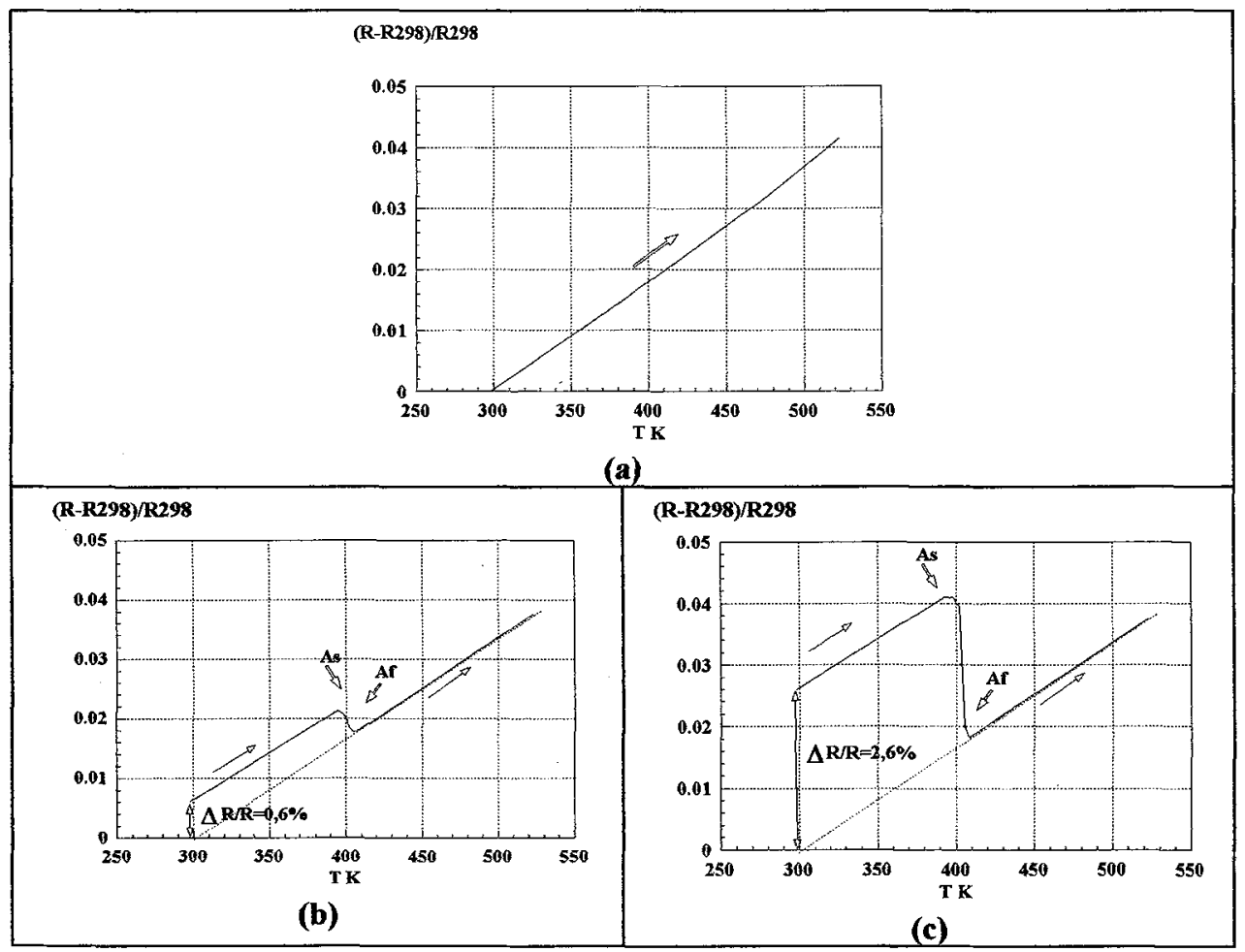

Fig. 3 :Appearance of the martensitic transformation at $298 \mathrm{~K}$ for a $1323 \mathrm{~K}$ as quenched sample of F.M.30 steel ; (a) : immediately after quenching, (b) : after 48 h., (c) : after $280 \mathrm{~h}$. 


\subsection{Samples slowly cooled from 1323K.}

Samples of F.M.30 and A.V.E steels were heated for $15 \mathrm{mn}$ at $1323 \mathrm{~K}$ under a $0.7510^{-6}$ Torr pressure. After cooling at $4 \mathrm{~K} . \mathrm{mn}^{-1}$, the samples were not oxidized but the F.M.30 alloy was then strongly attracted by a magnet.

$\mathrm{X}$-ray diffraction experiments yielded the following results:

-for the F.M.30 alloy, DO3 + $\mathrm{B}_{2}$ structures were detected with a lattice parameter $\mathrm{a}=0.568 \mathrm{~nm}$ corresponding to the $\mathrm{Fe}_{3} \mathrm{Si}$ ( or $(\mathrm{Fe}, \mathrm{Mn})_{3} \mathrm{Si}$ ) phase.

-for the A.V.E. alloy, we determined a mixture of the ordered stuctures $(a=0.570 \mathrm{~nm}$ for $D O 3$ ) and of the f.c.c. phase with a lattice parameter, $a=0.358 \mathrm{~nm}$, slightly smaller than those obtained before the thermal treatment $(a=0.361 \mathrm{~nm})$.

\subsection{Shape memory effect}

Taking in account the present results, plates $\left(1 \times 50 \times 5 \mathrm{~mm}^{3}\right)$ of the two alloys were water quenched after maintaining $1 \mathrm{~h}$ at $873 \mathrm{~K}$. After electropolishing, samples were strained of $2.5 \%$ and $4.5 \%$ respectively on a tensile machine at $\dot{\varepsilon}=1.75 .10^{-4} \mathrm{~s}^{-1}$. The shape memory recovery was obtained from dilatometric measurements with a maximum temperature of $573 \mathrm{~K}$ or $873 \mathrm{~K}$. The results are the following:

\begin{tabular}{|c|c|c|c|c|}
\cline { 3 - 5 } \multicolumn{2}{c|}{} & \multicolumn{3}{c|}{$\begin{array}{c}\text { Shape recovery } \\
(\mathrm{r} \pm 5 \%)\end{array}$} \\
\hline \multirow{2}{*}{ Steel } & $\begin{array}{c}\text { Strain } \\
(\varepsilon \pm 5 \%)\end{array}$ & $\begin{array}{c}573 \mathrm{~K} \\
1^{\text {st }} \text { cycle }\end{array}$ & $\begin{array}{c}873 \mathrm{~K} \\
1^{\text {st }} \text { cycle }\end{array}$ & $\begin{array}{c}873 \mathrm{~K} \\
3^{\mathrm{d}} \text { cycle }\end{array}$ \\
\hline \multirow{2}{*}{ F.M. 30 } & $2,5 \%$ & $80 \%$ & $90 \%$ & $95 \%$ \\
\cline { 2 - 5 } & $4,5 \%$ & $45 \%$ & $70 \%$ & $80 \%$ \\
\hline \multirow{2}{*}{ A.V.E. } & $2,5 \%$ & $70 \%$ & $75 \%$ & $85 \%$ \\
\cline { 2 - 5 } & $4,5 \%$ & $40 \%$ & $45 \%$ & $75 \%$ \\
\hline
\end{tabular}

Table 2

\section{DISCUSSION}

For the two alloys, the Ms temperature was higher than the Néel point. During cooling, the formation of the $\varepsilon$ martensite occurred between these two temperatures. However the transformation was not complete and the Mf temperature was used.

When $\mathrm{T}_{\mathrm{N}}^{\gamma}>\mathrm{Mf}$ (case of the F.M.30 steel), the growing of the $\varepsilon$ martensite plates formed at Ms went on from $\mathrm{T}_{\mathrm{N}}^{\gamma}$ to $\mathrm{Mf}$.

It is well known that shape memory steels are very sensitive to the chemical composition and to the thermal treatments. 
The effect of the quenching temperature was clearlyshown in the case of the F.M.30 alloy. At higher temperature than $873 \mathrm{~K}$, the reverse austenite was unstable but thermal induced $\varepsilon$ martensite was not obtained immediately after water quenching. This $\varepsilon$ martensite would be formed by a stress relaxation as a function of time at room temperature, which is followed by electrical resistance measurements. This result is in agreement with our observations of a thermal martensite localized at the surface of the alloy $(2,3)$.

The $\gamma$ phase is stabilized in the F.M.30 alloy at temperatures lower than $873 \mathrm{~K}$ whereas, in the case of the A.V.E. alloy, the stability is related to the chemical composition (Ms is lowered by the $\mathrm{Ni}$ and $\mathrm{Cr}$ contents).

Due to these considerations, the quenching temperature was chosen to $873 \mathrm{~K}$ for the two alloys. Table 2 shows that a $2.5 \%$ prestrain is a more suitable deformation for a good shape memory effect. The higher the annealing temperature was, the better was the recovery for the F.M.30 steel. The influence of the thermomechanical cycles is more important for the A.V.E. alloy than for the F.M.30 steel.

About the peculiar effect of a slow cooling from 1323K under vacuum, it can be said that an atomic ordering effect appeared. It was considered that Fe-Mn alloys showed an INVAR anomaly. During heating, a clustering effect of manganese atoms, rather than a short range order like in $\mathrm{Fe}-\mathrm{Ni}$ alloys (5), appeared. The unlike next neighbouring of the $\mathrm{Fe}$ atoms led the way to the appearance of the ferromagnetic state of this element (6). At $1323 \mathrm{~K}$, the vacancy concentration is high enough to permit a rapid diffusion of $\mathrm{Si}$ atoms (7) and enhanced the development of a ferromagnetic c.c. phase. From results on Fe-Si alloys $(8,9)$ the ordering would appear only from a disordered state during a slow cooling. It was claimed that in a Fe-21.6 at \% Mn-5.8 at \% Si-2.9 at \% $\mathrm{Ti}$ alloy, due to the manganese content, the $\mathrm{Fe}_{3} \mathrm{Si}$ phase is formed rather than the $\mathrm{Fe}_{2} \mathrm{Ti}$ compound, the latter is favoured by chromium (10). The $\mathrm{X}$ ray diffraction patterns can be interpreted in the following way :

-from disordered state of F.M.30 steel during slow cooling, the $\mathrm{B}_{2}$ structure appears and gives rise to the DO3 structure, in the $800-950 \mathrm{~K}$ temperature range, certainly near the Curie temperature of the alloy (11).

-in the case of the A.V.E. alloy, with a slightly lower silicon content, the $\gamma$ phase is still detected due to the influence of chromium, and may be nickel percentages.

-if the iron content is less than $60 \mathrm{wt} \%(\mathrm{Fe}-8 \mathrm{Mn}-12 \mathrm{Co}-13 \mathrm{Cr}-6 \mathrm{Ni}-6 \mathrm{Si})$ only the $\gamma$ phase is detected after a $1323 \mathrm{~K}$ slow cooling.

It must be underlined that the effect of silicon atoms is not perfectly mastered. Experiments on the F.M.30 steel showed that when a $1323 \mathrm{~K}$ slow cooling was carried out under an argon atmosphere containing oxygen, the DO3 surstructure lines did not appear and a ferromagnetic c.c compound was detected at the grain boundaries : inside the grain, $\varepsilon$ martensite was observed. After a vacuum cooling of the F.M.30 steel, fine grain boundaries were observed without $\varepsilon$ martensite inside the grains. 


\section{CONCLUSIONS}

The shape memory effect was studied in two Fe-based shape memory steels: the results are in agreement with previous results (13). However an isothermal formation of $\varepsilon$ martensite was found at $298 \mathrm{~K}$ in a $1323 \mathrm{~K}$ as quenched $\mathrm{Fe}-\mathrm{Mn}-\mathrm{Si}$ alloy. During a $1323 \mathrm{~K}$ slow cooling under vacuum the $\mathrm{DO3}$ structure, $(\mathrm{Fe}, \mathrm{Mn})_{3} \mathrm{Si}$, was observed probably related to the silicon and manganese contents of the alloys.

\section{References}

[1] K. TAMARAT, V. STAMBOULI, T. BOURAOUI and B. DUBOIS, $J$. de Physique IV, C4 Sup.au J. de Physique III, 1 (1991), C4-347.

[2] K. TAMARAT, G. ANDRE and B. DUBOIS, Proc. ICOMAT Monterey 1992, (1992), 1181.

[3] K. TAMARAT, thesis University of Paris 6, 1995

[4] K. TAMARAT, M. ESCORNE, A. PERCHERON-GUEGAN and B. DUBOIS, $J$. de Physique IV, C2 Sup.au J. de Physique III, 5 (1995), C2-89.

[5] T. TAKADEMA and S. KOMURA, J. de Physique, C2 Sup.au J. de Physique $n^{\circ} 3,40$ (1979), C2-165.

[6] W. F. SCHLOSSER, J. A. P. 42, 4 (1971), 1700.

[7] W. BATZ, H. W. MEAD and C.E. BIRCHENAL, J. of Met., (1952), 1070

[8] F. W. GLASER and W. IVANICK, J. of Met., (1956), 1256.

[9] T. SABURI, S. NENNO and M. YAMAMOTO, Proc. ICSMA Tokyo 1967- Trans. JIM, 9 (1968), 278.

[10] J. MARANDEL, B. SCHMITT and M. GANTOIS, Mem. Sci. Rev. Met. 70, 10 (1973), 4.

[11] P. R. SWANN, L. GRÅNÅS and B. LETHINEN, Met. Sci., 9 (1975), 90.

[12] A. SATO, E. CHISHIMA, K. SOMA and T. MORI, Acta. Metall., 30 (1982), 1177.

[13] H. OTSUKA, H. YAMADA, H. TANAHASHI and T. MARUYAMA, Mat. Sc. Forum, 56-58 (1990), 655. 